\title{
Isolamento de Candida spp. com utilização de meio de cultura cromogênico CHROMagar Candida
}

\section{Isolation of Candida spp. using of the chromogenic culture medium CHROMagar Candida}

\author{
Patrícia Monteiro RIBEIRO \\ Doutora em Biopatologia Bucal - Faculdade de Odontologia de São José dos Campos - UNESP - São José dos Campos \\ - SP - Brasil.
}

\section{Cristiane Yumi KOGA ITO}

Professora Adjunta - Departamento de Biociências e Diagnóstico Bucal - Faculdade de Odontologia de São José dos Campos - UNESP - São José dos Campos - SP - Brasil.

\section{Juliana Campos JUNQUEIRA}

Professora Assistente - Departamento de Biociências e Diagnóstico Bucal - Faculdade de Odontologia de São José dos Campos - UNESP - São José dos Campos - SP - Brasil.

\section{Antonio Olavo Cardoso JORGE}

Professor Titular - Departamento de Biociências e Diagnóstico Bucal - Faculdade de Odontologia de São José dos Campos - UNESP - São José dos Campos - SP - Brasil.

\begin{abstract}
Resumo
O objetivo do presente estudo foi comparar o isolamento e identificação de leveduras do gênero Candida em meio de cultura cromogênico CHROMagar Candida com o isolamento convencional em ágar Sabouraud dextrose com cloranfenicol. Foram coletadas amostras de saliva de 50 indivíduos com idades entre 13 e 70 anos. Os participantes realizaram enxágue bucal com solução fisiológica esterilizada e tamponada com fosfato (PBS) durante $30 \mathrm{~s}$. Essas amostras foram semeadas em CHROMagar Candida e ágar Sabouraud dextrose com cloranfenicol e incubadas a $37^{\circ} \mathrm{C}$ por $48 \mathrm{~h}$. A seguir, foi realizada a contagem de unidades formadoras de colônias (UFC/mL) em CHROMagar Candida e em ágar Sabouraud. Foi realizada a identificação presuntiva das espécies de Candida em CHROMagar através da observação da morfologia e cor das colônias. As colônias de Candida foram isoladas para identificação fenotípica convencional por meio das provas de produção de tubos germinativos, formação de hifas e clamidoconídeos, fermentação e assimilação de açúcares, diferencial de temperatura e urease. Os isolados identificados como C. albicans também foram analisados genotipicamente, pela técnica de Reação em Cadeia da Polimerase, para diferenciação de C. dubliniensis. Os resultados demonstraram que o ágar Sabouraud apresentou maior contagem de leveduras (UFC/mL) em relação ao CHROMagar, entretanto sem diferença estatisticamente significante. O CHROMagar foi eficaz na pré-identificação de Candida albicans e Candida tropicalis. Concluiu-se que ambos os meios foram eficazes para o crescimento de leveduras, sendo que o ágar Sabouraud dextrose com cloranfenicol apresentou maior quantidade de UFC/mL. O CHROMagar possibilitou a identificação presuntiva da maioria das espécies de Candida.
\end{abstract}

\section{UNITERMOS}

Candida, C. albicans, ágar

\section{INTRODUÇÃO}

A incidência de colonização orofaringeana por Candida em adultos saudáveis apresenta resultados entre 3 a $48 \%$, já em crianças estas taxas se elevam entre $5,4 \%$ e $71,3 \%$. A presença de leveduras na cavidade bucal, entretanto, não implica em doença ${ }^{8,17}$.
O gênero Candida é composto por cerca de 150 espécies de leveduras, das quais algumas apresentam importância médica, incluindo C. albicans, C. tropicalis, C. parapsilosis, C. krusei, C. kefyr, C. glabrata, C. guilliermondii e C. dubliniensis S $^{3,5,17}$. 
C. dubliniensis foi descrita como nova espécie do gênero Candida em 1995, na Irlanda, por Sullivan et al. ${ }^{21}$. Inicialmente foi associada com candidose orofaríngea de pacientes infectados pelo HIV. Atualmente está relacionada a diversas patologias de diferentes graus de imunocomprometimento ${ }^{2}$. Um dos problemas que interferem na identificação dessa espécie é a confiabilidade nos métodos fenotípicos utilizados para a diferenciação das outras espécies do gênero Candida, uma vez que $C$. dubliniensis é fenotipicamente similar à C. albicans ${ }^{1}$.

Alguns métodos fenotípicos foram propostos para diferenciar espécies de C. albicans e C. dubliniensis, incluindo o diferencial de temperatura. C. albicans consegue manter crescimento a $45^{\circ} \mathrm{C}$ enquanto que C. dubliniensis geralmente não apresenta crescimento nesta temperatura. Este teste fenotípico muitas vezes torna-se inviável por sua pouca especificidade, requerendo testes genotípicos para confirmação dos isolados ${ }^{11}$.

O gênero Candida spp. é o quarto grupo mais comum de patógenos nosocomiais isolados de pacientes sob cuidados médicos, cirúrgicos e provenientes de unidades de terapia intensiva e o isolamento e métodos de identificação utilizados rotineiramente podem falhar no isolamento de cepas a partir de culturas mistas de leveduras ${ }^{23}$.

O ágar Sabouraud Dextrose (Difco Laboratories, Ltda, MI, EUA) é o meio de cultura de escolha para o isolamento de leveduras do gênero Candida spp. por inibir o crescimento da maioria de espécies bacterianas, e se torna mais seletivo com a adição do cloranfenicol (Carlo Erba, 0,1 mg por mL de meio).

O meio de cultura CHROMagar Candida (CHROMagar, Microbiology, Paris, França) por conter substâncias cromogênicas, é útil para verificação de diferentes cepas de leveduras numa mesma amostra, permitindo a identificação presuntiva rápida de infecção fúngica mista, fornecendo ainda identificação presuntiva de algumas espécies de leveduras de interesse clínico ${ }^{4,13}$. Segundo as instruções do fabricante, cepas de Candida albicans, C. tropicalis e C. krusei podem ser pré identificadas por este método. Por ser cromogênico, o meio modifica as colônias destas espécies respectivamente para as cores verde, azul e rosa ${ }^{14}$. O isolamento diferencial com um meio de cultura cromogênico permite detectar quais candidoses são ocasionadas por mais de uma espécie do gênero Candida, permitindo tratamento antifúngico precoce e melhor adaptado ${ }^{23}$.

O objetivo do presente trabalho foi comparar o isolamento e a capacidade de identificação presuntiva do meio de cultura CHROMagar Candida com o isolamento convencional em ágar Sabouraud Dextrose com cloranfenicol e identificação fenotípica convencional.

\section{Material e Métodos}

\section{Seleção dos participantes da pesquisa}

Participaram do presente estudo 50 indivíduos, com idades entre 13 e 70 anos, sendo 40 do gênero masculino $(80 \%)$ e 10 do feminino $(20 \%)$. Estes indivíduos não apresentavam evidência clínica de candidose bucal, não utilizavam antifúngicos ou qualquer tipo de terapia imunossupressora. O projeto de pesquisa foi aprovado pelo Comitê de Ética em Pesquisa da Faculdade de Odontologia de São José dos Campos/UNESP, sob protocolo 096/2004-PH/ CEP.

\section{Coleta e cultivo das amostras de Candida}

Para cada participante foi fornecido $10 \mathrm{~mL}$ de solução fisiológica ( $\mathrm{NaCl}$ a $0,85 \%)$ esterilizada e tamponada com fosfato $0,1 \mathrm{M}$ e $\mathrm{pH} 7,2$ (PBS), em um coletor universal estéril descartável. As coletas de saliva foram realizadas no período da manhã, após desjejum e higiene bucal rotineira. Cada indivíduo realizou enxague bucal durante 30 segundos e a seguir devolveu o conteúdo ao coletor previamente identificado. Cada amostra foi centrifugada a $2.300 \mathrm{X} g$ por 10 minutos, sendo o sobrenadante descartado. A seguir, o depósito foi ressuspendido em 2,5 mL de PBS e misturado em agitador de tubos (Vortex) por 30 segundos, produzindo assim a suspensão de concentração final. Respeitou-se o período máximo de 3 horas entre a coleta e o processamento das amostras.

Das suspensões obtidas, foram semeadas $0,1 \mathrm{~mL}$ em ágar Sabouraud dextrose (Difco) com cloranfenicol (Carlo Erba, 0,1 mg por mL de meio) em duplicata e em CHROMagar (CHROMagar, Microbiology, Paris - França) também em duplicata. As placas foram incubadas a $37^{\circ} \mathrm{C}$ por 48 horas e a seguir por mais cinco dias a temperatura ambiente. Após crescimento das colônias de Candida, foi realizada a contagem de unidades formadoras de colônias (UFC) em ágar Sabouraud e CHROMagar Candida. Além disso, nas placas de CHROMagar foi feita a identificação presuntiva das espécies de Candida baseada na morfologia e cor das colônias (Quadro 1) . 


\section{Quadro 1 - Cor e morfologia das colônias de Candida em CHROMagar Candida segundo instruções do fabricante}

\begin{tabular}{|ll|}
\hline Cor típica da colônia & $\begin{array}{l}\text { Microrganismo } \\
\text { pré-identificado }\end{array}$ \\
\hline Verde & C. albicans \\
Azul metálico & C. tropicalis \\
Rosa, rugosa & C. krusei \\
Branca a rosa & Outras espécies \\
\hline
\end{tabular}

As colônias do ágar Sabouraud e CHROMagar foram transferidas para ágar Sabouraud dextrose inclinado, para obtenção de culturas puras, as quais foram posteriormente identificadas. Foram isoladas todas as colônias que apresentaram morfologia ou coloração diferente em CHROMagar.

\section{Identificação fenotípica convencional das espécies de Candida}

Os isolados foram identificados de acordo com Sandvén ${ }^{18}$, realizando-se as seguintes provas de identificação: capacidade de produção de tubo germinativo em soro estéril de coelho, formação de clamidoconídeos e hifas em Corn Meal Ágar adicionado de 1\% de Tween 80 , fermentação e assimilação de carboidratos (glicose, maltose, lactose, sacarose, galactose e rafinose).

Como C. dubliniensis possui características fenotípicas comuns a C. albicans, foi utilizado o diferencial de temperatura como método de diagnóstico presuntivo de C. dubliniensis. A partir das cepas identificadas como C. albicans nas provas de identificação citadas anteriormente, fez-se uma cultura pura de 24 horas em ágar Sabouraud dextrose e incubou-se em estufa a $42^{\circ} \mathrm{C}$ por 48 horas. Ao contrário de $C$. albicans, $C$. dubliniensis não cresce, ou cresce pobremente a essa temperatura ${ }^{15}$.

Além disso, as colônias vermelho-alaranjadas isoladas do ágar Sabouraud dextrose com cloranfenicol, foram submetidas à prova da urease para identificação de Rodothorula. Uma alçada da cultura pura de levedura foi adicionada à $1 \mathrm{~mL}$ do meio de Christensen (Difco), diluído em $100 \mathrm{~mL}$ de água destilada. Após 2 horas de incubação a $37^{\circ} \mathrm{C}$, a mudança da cor do meio de vermelho para rosa solferino (urease positivo) confirmou o diagnóstico de Rodothorula rubra.

\section{Identificação genotípica de $C$. dubliniensis}

As espécies identificadas fenotipicamente como C. albicans foram submetidas à análise molecular para diferenciação de $C$. dubliniensis. A identificação genotípica de $C$. dubliniensis foi realizada seguindo três etapas: extração do DNA das cepas isoladas, reação em cadeia da polimerase (PCR) e visualização dos produtos obtidos na PCR por eletroforese em gel de agarose, de acordo com a metodologia descrita por MahnB et al. ${ }^{9}$. A mistura para PCR foi composta por $2 \mu \mathrm{L}$ de DNA da amostra a ser testada, $1 \mu \mathrm{L}$ de cada primer utilizado na reação (Uni-f: 5'-GCATATCAATAAGCGGAGGAAAAG-3'; Unir: 5'GGTCCGTGTTCAAGACG-3'; DUBF Act-f: 5'GTATTTGTCGTTCCCCTTTC-3'; e DUBR Act-r: 5'-GTGTTGTGTGCACTAACGTC-3'), 12,5 $\mu$ L de PCR Master Mix (Promega, Madison, WI, EUA) e 6,5 $\mu \mathrm{L}$ de água para biologia molecular desmineralizada (Invitrogen, CA, EUA). A seguir a amostras foram para o termociclador automático (MastercyclerEppendorf, Hamburgo, Alemanha) e submetidas às seguintes condições cíclicas: 3 minutos a $95^{\circ} \mathrm{C}$ (desnaturação) seguidos de 30 ciclos de 30 segundos a $95^{\circ} \mathrm{C}$ (amplificação), 30 segundos a $58^{\circ} \mathrm{C}$ (anelamento dos primers), 60 segundos a $72^{\circ} \mathrm{C}$ (extensão), seguidos por 10 minutos a $72^{\circ} \mathrm{C}$ no último ciclo (extensão final).

\section{Análise estatística}

A estatística dos resultados foi realizada pelo teste $t$ de Student com nível de significância de 5\% (p $\leq$ 0,05), utilizando-se o programa Minitab (Minitab Inc, State College, PA, EUA), versão 13.1.

\section{Resultados}

As leveduras do gênero Candida estavam presentes em $28(56 \%)$ dos indivíduos estudados. Houve crescimento de Candida nas placas de ágar Sabouraud para os 28 indivíduos portadores de leveduras na cavidade bucal. Em relação ao CHROMagar Candi$d a$, houve crescimento nas placas de 27 indivíduos portadores do gênero Candida. O número de UFC/ $\mathrm{mL}$ encontrado nas placas de ágar Sabouraud foi superior ao número de $\mathrm{UFC} / \mathrm{mL}$ observado nas placas de CHROMagar, entretanto sem diferença estatisticamente significante entre os grupos (Tabela 1). 
Tabela 1 - Comparação pelo teste $t$ de Student das médias de UFC/mL (Log) encontradas em ágar Sabouraud dextrose com cloranfenicol e CHROMagar Candida

\begin{tabular}{llllll}
\hline Meios de cultura & Média & Desvio-padrão & Valor Mínimo & Mediana & Valor Máximo \\
\hline Ágar Sabouraud & 2,74 & 0,77 & 1,60 & 2,53 & 4,58 \\
CHROMagar & 2,54 & 1,01 & 0 & 2,53 & 4,34 \\
\hline
\end{tabular}

*Não existe diferença estatisticamente significativa $(p=0,427)$

Dos 28 indivíduos positivos para o gênero Candida na cavidade bucal, foram isoladas 40 cepas de Candida. O meio CHROMagar permitiu identificar colônias distintas por ser cromogênico, possibilitando maior número de isolamento.

Essas 40 cepas de Candida foram identificadas fenotipicamente pelos métodos convencionais, sendo encontrado $19(47,5 \%)$ de C. albicans e $21(52,5 \%)$ de espécies não albicans. Entre as espécies não albicans, foram identificadas 7 cepas de Rodothorula rubra, 4 C. stellatoidea, 3 C. glabrata, 2 C. tropicalis, $2 C$. Krusei, 1 C. guilliermondii e 2 amostras sugestivas de $C$. dubliniensis pelo diferencial de temperatura.

Todas as amostras de C. albicans e sugestivas de C. dubliniensis foram analisadas por testes genotípicos, sendo que $100 \%$ das amostras testadas foram identificadas genotipicamente como C. albicans.

Em relação a identificação presuntiva no meio de cultura CHROMagar Candida pela morfologia e cor das colônias, observou-se que as colônias verdes em CHROMagar foram identificadas pelos métodos convencionais como $C$. albicans, com exceção de uma cepa, que foi identificada como $C$. stellatoidea. Todas as colônias azuis foram identificadas como $C$. tropicalis, indicando que o CHROMagar Candida foi capaz de identificar presuntivamente $100 \%$ das cepas de C. tropicalis.

Entre as duas cepas de C. krusei, apenas uma apresentou colônias rosas rugosas em CHROMagar conforme a instrução do fabricante. A outra cepa de C. krusei formou colônias de cor azul acinzentada. Colônias branca a rosa em CHROMagar foram identificadas fenotipicamente como C. glabrata e $C$. guilliermondii.

\section{Dıscussão}

No presente estudo foram analisados lavados bucais de 50 indivíduos saudáveis, comparando-se o isolamento de leveduras em meio de cultura ágar
Sabouraud dextrose com cloranfenicol e identificação fenotípica convencional com o isolamento e identificação presuntiva em CHROMagar Candida.

Os dois meios de cultura utilizados foram eficazes para o crescimento das cepas de Candida, entretanto observou-se maior número de UFC/mL de leveduras em ágar Sabouraud Dextrose com cloranfenicol em relação ao CHROMagar. Segundo Sivakumar et al..$^{20}$, o CHROMagar apresenta maior capacidade de inibir o crescimento bacteriano em relação ao ágar Sabouraud, e contém substratos cromogênicos que agem sobre as enzimas produzidas por microrganismos, levando a formação de colônias com diferentes pigmentações. Provavelmente, os fatores cromogênicos do CHROMagar tornam este meio mais seletivo e consequentemente levam também a inibição de alguns isolados de Candida.

Em relação a custos, o CHROMagar foi significativamente mais oneroso que o ágar Sabouraud dextrose com cloranfenicol, porém apresentou maior praticidade de trabalho.

Utilizando-se os métodos de identificação fenotípica convencional, foi encontrado $47,5 \%$ de $C$. albicans e 52,5\% de espécies não albicans entre os 40 isolados obtidos neste trabalho. Nadagir et al. ${ }^{12}$ (2008) isolaram leveduras do gênero Candida da cavidade bucal de 132 pacientes e encontraram $66,66 \%$ de $C$. albicans e 33,33\% de espécies não albicans. Em relação à identificação presuntiva em CHROMagar, foi verificado que $C$. albicans apresentou cor verde em $100 \%$ das amostras. É importante ressaltar que 1 amostra identificada como C. albicans em CHROMagar, foi identificada pelos testes fenotípicos convencionais como $C$. stellatoidea, que atualmente é considerada uma variante de $C$. albicans. C. tropicalis também exibiu cor azul em todas as amostras. Estes achados concordam com estudos de Odds \& Bernaerts ${ }^{13} \mathrm{e}$ Pfaller et al. ${ }^{14}$, que encontraram índices acima de $95 \%$ dos isolados de C.albicans e C. tropicalis corretamente pré-identificados por meio do CHROMagar. 
No presente trabalho, foram isoladas 2 cepas de C. krusei, sendo que apenas uma apresentou coloração rosa conforme relatado pelo fabricante do CHROMagar. Entretanto, Sivakumar et al. ${ }^{20}$ verificaram que os 40 isolados de C. krusei obtidos de candidose orofaríngea apresentaram colônias rosas de superfícies rugosas em CHROMagar Candida.

Giusiano \& Mangiaterra ${ }^{6}$ concluíram que o meio de cultura CHROMagar Candida apresenta grande utilidade para a identificação presuntiva rápida de leveduras, especialmente em pacientes imunocomprometidos. Nos casos de infecção fúngica em pacientes imunossuprimidos, quanto mais rápida for feita a identificação do microrganismo, ainda que presuntivamente, mais rápido será estabelecido o tratamento adequado, diminuindo assim a incidência de candidose disseminada, que está frequentemente associada com os casos de óbito em pacientes imunossuprimidos ${ }^{5,22}$.

Neste estudo, dois isolados foram sugestivos de $C$. dubliniensis pelo teste de diferencial de temperatura, entretanto após a realização da identificação genotípica, verificou-se que esses isolados eram C. albicans. Esses dados sugerem que o diferencial de temperatura não é um método seguro para identificação presuntiva de $C$. dubliniensis. A procura de um marcador fenotípico ideal de diferenciação entre C. albicans e $C$. dubliniensis fez com que recentemente houvesse uma proliferação de publicações sobre o comportamento destas duas espécies quando semeadas em meios de cultura suplementados com extratos de plantas, como ágar girassol (Helianthus annus) e proteína derivada do leite, como ágar caseína, diferenças no perfil de assimilação de carboidratos entre outros ${ }^{1,2,11}$, porém concordamos com os autores que consideram o PCR o método mais eficiente para diferenciação entre estas duas espécies, embora muitos outros métodos moleculares tenham sido citados com a mesma finalidade ${ }^{9,19,21}$.
Muitos autores relataram que a identificação fenotípica presuntiva de $C$. dubliniensis também pode ser realizada pelo CHROMagar, pois segundo esses autores, as colônias de $C$. dubliniensis apresentam cor verde escuro no CHROMagar e as colônias de $C$. albicans em verde mais claro ${ }^{10,16,19}$. Entretanto, essas informações não constam nas instruções do fabricante do CHROMagar Candida. Além disso, foi verificado neste estudo, que as colônias de C. albicans apresentaram diversos tons de verde, que variaram do claro para o escuro, sendo muitas vezes observadas na mesma placa de CHROMagar.

A rápida identificação de um agente causador de infecção fúngica, ainda que presuntiva, como a que pode ser obtida através da utilização do CHROMagar Candida, e o início imediato da medicação antifúngica mais apropriada, pode fazer significativa diferença para os casos de pacientes imunocomprometidos, porém não descarta em hipótese alguma, a identificação definitiva das espécies de leveduras envolvidas nestes casos.

\section{Conclusão}

A análise dos resultados obtidos permitiu as seguintes conclusões: os meios de cultura ágar Sabouraud Dextrose com cloranfenicol e CHROMagar Candida foram eficazes para o crescimento e isolamento de leveduras da cavidade bucal; o ágar Sabouraud dextrose com cloranfenicol apresentou maior quantidade de unidades formadoras de colônias na saliva (UFC/ $\mathrm{mL}$ ) de leveduras do gênero Candida em relação ao CHROMagar, porém sem diferença estatisticamente significante; o meio de cultura CHROMagar foi eficaz na identificação presuntiva da maioria das leveduras do gênero Candida.

\footnotetext{
ABstract

The aim of this study was to compare the isolation and identification of yeasts of gender Candida by medium CHROMagar Candida with the convencional medium Sabouraud Dextrose agar with chloramphenicol. Fifty samples of saliva were collected from individuals between 13 to 70 years old. The individuals rinsed their mouth with sterile phosphate buffered saline (PBS) for 30 seconds. Those samples were plated in CHROMagar Candida and Sabouraud Dextrose agar with chloramphenicol, and incubated at $37^{\circ} \mathrm{C}$ for $48 \mathrm{~h}$. After that, the number of colony-forming units per $\mathrm{mL}(\mathrm{CFU} / \mathrm{mL}) \mathrm{were}$ counted in CHROMagar Candida and Sabouraud Dextrose agar. The presumptive identification of Candida species in CHROMagar was carried out by color and morphology of colonies. The Candida colonies were isolated in order to perform phenotypic identification through the production of germinative tubes, presence of hyphae and chlamydospores, carbohydrate fermentation and assimilation, temperature differentiate, and urease test. The isolates identified as $C$.
} 
albicans were analyzed by genotypic characterization using the Polymerase Chain Reaction (PCR) to discriminate $C$. dubliniensis. The results demonstrated that Sabouraud Dextrose agar presented higher number of Candida $(\mathrm{CFU} / \mathrm{mL})$ in relation to the CHROMagar, however no statistical difference was observed. The CHROMagar was effective for presumptive identification of $C$. albicans and $C$. tropicalis. It was concluded that both medium were effective for growing of yeasts, with higher number of UFC/mL in CHROMagar. The CHROMagar allowed the presumptive identification of the most Candida species.

\section{UNITERMS}

Candida; C. albicans; Agar.

\section{REFERÊNCIAS}

1. Al Mosaid A, Sullivan D, Salkin IF, Shanley D, Coleman DC. Differentiation of Candida dubliniensis from Candida albicans on Staib agar and caffeic acid-ferric citrate agar. J Clin Microbiol. 2001;39(1):323-7.

2. Alves SH, Horta JA, Milan EP, Scheid LA, Vainstein MH, Santurio JM, et al. Carboydrate assimilation profiles of brazilian Candida dubliniensis isolates. Rev Inst Med Trop São Paulo. 2005;47(2):109-11.

3. Cannon RD, Holmes AR, Mason AB, Monk BC. Oral Candida: clearance, colonization, or candidiasis? J Dent Res. 1995;74(5):1152-61.

4. Garcia-Matos P, Mira-Gutierrez J, Galan-Sanches F, Hernandez-Molina JM. Usefulness of the CHROMagar Candida culture medium in differentiation and presumed identification of yeast of clinic interest. Enferm Infecc Microbiol Clin. 1997;15(2):70-2.

5. Grossi, P, Farina C, Fiocchi R, Gasperina DD. Prevalence and outcome of invasive fungal infections in 1,963 thoracic organ transplant recipients. A multicenter retrospective study. Transplantation. 2000;70(1):112-6.

6. Giusiano GE, Mangiaterra ML. Diferenciación e identificación presuntiva rápida de levaduras com el medio CHROM-agar Candida. Rev Arg de Microbiol. 1998;30(2):100-3.

7. Jabra-Rizk MA, Baqui AAMA, Kelley JI, Falkler Junior. WA, Merz WG, Meiller TF. Identification of Candida dubliniensis in a prospective study of patients in the United States. J Clin Microbiol. 1999;37(2):321-6.

8. Jorge AOC, Koga-Ito CY, Gonçalves CR, Fantinato V, Unterkircher CS. Presença de leveduras do gênero Candida na saliva de pacientes com diferentes fatores predisponentes e de indivíduos controle. Rev Odontol Univ São Paulo. 1997;11(4):279-85.

9. Mähnß B, Stehr F, Schäfer W, Neuber K. Comparison of standard phenotypic assays with a PCR method to discriminate Candida albicans e Candida dubliniensis. Mycoses. 2005;48(1):55-61.

10. Meis JFGM, Ruhnke M, Pauw BE, Odds FC, Siegert W, Verweij PE. Candida dubliniensis candidemia in patients with chemotherapyinduced neutropenia and bone marrow transplantation. Emerg Infect Dis. 1999;5(1):150-3.

11. Mosca CO, Moragues MD, Brena S, Rosa AC, Ponton J. Isolation of Candida dubliniensis in a teenager with denture stomatitis. Med Oral Patol Oral Cir Bucal. 2005;10(1):28-31.

12. Nadagir SD, Chunchanur SK, Halesh LH, Yasmeen K, Chandrasekhar MR, Patil BS. Significance of isolation and drug susceptibility testing of non-Candida albicans species causing oropharyngeal candidiasis in HIV patients. Southeast Asian J Trop Med Public Health. 2008;39(3):492-5.

13. Odds FC, Bernaerts R. CHROMagar Candida, a new differential isolation medium for presumptive identification of clinically imporrtant Candida species. J Clin Microbiol. 1994;32(8): 923-9.
14. Pfaller MA, Houston A, Coffmann S. Application of CHROM agar Candida for rapid screening of clinical specimen for Candida albicans, Candida tropicalis, Candida krusei, and Candida (Torulopsis) glabrata. J Clin Microbiol. 1996;34(1):58-61.

15. Pinjón E, Sullivan D, Salkin I, Shanley D, Coleman D. Simple, inexpensive, reliable method for differentiation of Candida dubliniensis from Candida albicans. J Clin Microbiol. 1998;36(7):2093-5.

16. Salkin IF, Pruitt WR, Padhye AA, Sullivan D, Coleman D, Pincus DH. Distinctive carbohydrate assimilation profiles used to identify the first clinical isolates of Candida dubliniensis recovered in the United States. J Clin Microbiol. 1998;36(5):1467.

17. Samaranayake YU, Samaranayake LP. Experimental oral candidiasis in animal models. Clin Microbiol Rev. 2001;14(2):398-429.

18. Sandven P. Laboratory identification and sensitivity testing of yeast isolates. Acta Odontol Scand. 1990;48(1):27-36.

19. Schorling SR, Kortinga HC, Froschb M, Mühlschlegel FA. The role of Candida dubliniensis in oral candidiasis in human immunodeficiency virus-infected individuals. Crit Rev Microbiol. 2000;26(1):59-68.

20. Sivakumar VG, Shankar P, Nalina K, Menon T. Use of CHROMagar in the differentiation of common species of Candida. Mycopathology. 2009; 167(1):47-9.

21. Sullivan DJ, Westerneng TJ, Haynes kA, Bennett DE, Coleman DC. Candida dubliniensis sp. nov.: phenotypic and molecular characterization of a novel species associated with oral candidosis in HIV-infected individuals. Microbiology. 1995;141(7):1507-21.

22. Uip DE, Amato Neto V, Strabelli TMV, Bocchi EA, Fiorelli A, Stolf N, et al. Infecções em 100 pacientes submetidos a transplante cardíaco. Arq Bras Cardiol. 1996;64(6):537-40.

23. Yera H, Poulain D, Lefebvre A, Camus D, Sendid B. Polymicrobiol candidaemia revealed by peripheral blood smear and chromogenic medium [Short Report]. J Clin Pathol. 2004;57(2):196-8.

Recebido em 11/03/2010 Aprovado em 21/06/2010

Correspondência: Antonio Olavo Cardoso Jorge

Endereço: Faculdade de Odontologia de São José dos Campos -

UNESP,

Departamento de Biociências e Diagnóstico Bucal Av. Francisco José Longo, 777, São José dos Campos - SP, 12.245-000, Brasil. e-mail: olavojorge@fosjc.unesp.br. 